\title{
Catastro multipropósito sostenible: una necesidad inaplazable
}

\author{
Manuel-G. Alcázar Molina*
}

Recibido el 3 de marzo de 2015; aceptado el 16 de agosto de 2015

\begin{abstract}
Sustainable multipurpose cadastre is essential to consolidate the country as an articulated territory, integrated and cohesive in the physical, economic and social fields within its natural geographical environment tool. This will impact on a balanced social development that improves the quality of life of its citizens, encouraged by a better and more efficient management of public resources.

But even considering a goal in many initiatives, sustainable multipurpose cadastre should be seen as a prerequisite for achieving real, dynamic, fast, reliable, and especially helpful territorial infrastructure.

This document presents a multidisciplinary view of a multipurpose cadastre, identifying those parameters that are considered fundamental for a efficient, sustainable over time and reliable product. It exposes and develops a logical sequence for its construction, identifying the most common problems that may arise, followed by solutions for them. All within the technical and legal independence of each model built, intended to meet the specific needs for which it is designed, but with a clear global vision.
\end{abstract}

Key words: multipurpose cadastre, cadastral projects, land information structure, real estate valuation.

\section{Resumo}

O cadastro multifinalitário sustentável é a ferramenta fundamental para consolidar o país como território articulado, integrado e coeso nos âmbitos físico, econômico e social, dentro do seu entorno geográfico natural. Ele resultará em um desenvolvi-

* Doctor, ingeniero, profesor titular de Universidad de Jaén, Campus Las Lagunillas, s/n, Edif. A-3, despacho 335, 23071, Jaén, España. Funcionario de la Dirección General de Catastro de España (en excedencia voluntaria),correo electrónico: malcazar@ujaen.es 
mento social equilibrado que melhore a vida dos cidadãos, estimulado por uma gestão de recursos públicos melhor e mais eficaz.

No entanto, mesmo sendo o objetivo de várias iniciativas, o cadastro multifinalitário sustentável deve inicialmente chegar em uma infraestrutura territorial verdadeiramente dinâmica, ágil, confiável e útil.

Este documento oferece uma visão multidisciplinar de um cadastro multifinalitário, identificando aqueles parâmetros que se consideram fundamentais para se obter um produto eficiente, sustentável ao longo do tempo e confiável. Se apresenta e desenvolve uma sequência lógica para sua construção, identificando os problemas mais comuns que podem se apresentar, seguido da exposição de soluções para os mesmos. Tudo isso dentro da independência técnico-jurídica de cada modelo construído, destinado a satisfazer as necessidades específicas considerando-se uma visão globalizada clara.

Palavras chave: cadastro multifinalitário, projetos cadastrais, infraestrutura de informação territorial, valorização imobiliária.

\section{Resumen}

El catastro multipropósito sostenible es la herramienta fundamental para consolidar al país como un territorio articulado, integrado y cohesionado en los ámbitos físico, económico y social, dentro de su entorno geográfico natural. Ello repercutirá en un desarrollo social equilibrado que mejore la calidad de vida de sus ciudadanos, estimulado por una mejor y más eficaz gestión de los recursos públicos.

Pero, aun considerándolo una meta en muchas iniciativas, el catastro multipropósito sostenible debe contemplarse como un paso previo para lograr una verdadera infraestructura territorial, dinámica, ágil, confiable y especialmente, útil.

En este documento se ofrece una visión pluridisciplinar de un catastro multipropósito, identificando aquellos parámetros que se consideran fundamentales para lograr un producto eficiente, sostenible en el tiempo y confiable. Se expone y desarrolla una secuencia lógica para su construcción, identificando los problemas más comunes que pueden presentarse, seguido de la exposición de soluciones para los mismos. Todo ello dentro de la independencia técnico-jurídica de cada modelo construido, destinado a satisfacer las necesidades específicas para las que se diseña, pero con una clara visión globalizadora.

Palabras clave: catastro multipropósito, proyectos catastrales, infraestructura de información territorial, valoración inmobiliaria.

\section{Consideraciones}

Como cualquier propuesta técnico-administrativa rigurosa que se ponga en marcha, en primer lugar hay que identificar los objetivos que se persiguen, los plazos de 
ejecución y los recursos económicos, personales y políticos disponibles. De la mano de un plan estratégico se pueden organizar y definir el futuro de la institución catastral; especialmente cuando se estén replanteando procesos de implantación catastral o de un cambio sustancial del existente por no satisfacer las necesidades previstas. Este plan debe ir seguido por otro-s operativo-s que detallen los objetivos y metas, establezca una temporalización viable y defina las estrategias a seguir; sin olvidar las fuentes de financiación, así como los procesos de control y seguimiento.

Los proyectos catastrales son complejos. A su concepción y diseño se une la gestión y explotación de una información muy sensible en determinados aspectos, como es el reconocimiento de derechos sobre inmuebles y su puesta en tributación; lo que, en ocasiones, ha sido el motivo de su fracaso. Si se estudia la historia catastral son más numerosas las iniciativas fallidas que las culminadas, y no por cuestiones técnicas, sino más bien por la presión de colectivos perfectamente identificados:

I. Aquellos titulares de numerosos y valiosos inmuebles que gozan de una cómoda situación fiscal encubierta en registros tributarios obsoletos, incompletos o, simplemente, falseados.

II. Aquellos profesionales que se benefician de largos y costosos procesos de titulación inmobiliaria.

III. Aquellos responsables políticos que no quieren enfrentarse con sus votantes ni destinar recursos económicos a proyectos que servirán para nutrir las arcas de rivales que los reemplazarán.

IV. Aquellos otros, por último, que pueden ver mermadas sus influencias y sus ingresos al existir bases de datos fiables, universales y públicos, al servicio de las instituciones, empresas y particulares.

En realidad el grupo anterior no es numeroso, pero sí influyente; por lo que tiene capacidad de presión para abortar los proyectos, antes incluso de nacer; o para ahogarlos al impedir que les lleguen los apoyos económicos y técnicos necesarios cuando están en marcha.

Por otra parte, el temor al incremento de la presión fiscal, favorecido por falta de formación e información (cultura catastral), invita a los pequeños propietarios a no declarar sus inmuebles; sin ser conscientes de las limitaciones que tienen las propiedades no formalizadas y del pequeño grado de fraude que supone esta decisión. La mayor parte de las administraciones tributarias recaudan sobre las bases imponibles existentes, y para alcanzar los niveles de ingresos previstos pueden incrementar los gravámenes sobre aquellas. Identificando todos los bienes y asignándole un valor equitativo y coordinado, el fraude se reduciría, se incrementarían las bases imponibles totales y habría justicia tributaria, con lo que podrían reducirse 
las deudas tributarias individuales; a la vez que se cumplirían con los preceptos legales establecidos a través de las leyes tributarias.

Una vez aceptada la base imponible, y su correspondiente deuda tributaria en concepto de impuesto predial (que a nadie agrada), los beneficios directos e indirectos de un catastro fiable, moderno, transparente y ágil son múltiples; especialmente en materia de titulación de tierras, reforma agraria, usos civiles y medioambientales de la documentación gráfica, políticas sociales, ordenación territorial, urbanismo, recuperación de plusvalías, etc. No queda, por tanto, más línea de actuación que la de perseguir la implantación de un modelo catastral acorde con las necesidades propias de cada país, que esté en consonancia con los de su entorno, huyendo, a corto plazo, de diseños excesivamente perfeccionistas y rigurosos que pueden llevar al suicidio del proyecto; así como de también deben obviarse "proyectos milagro", que solo generan un "simulacro catastral" cuya vida útil coincidirá con el plazo de garantía fijado por el promotor-ejecutor.

\section{Contenidos}

Como paso previo a la identificación de los objetivos hay que ser conscientes de que los registros de inmuebles y derechos deben adecuarse a las necesidades y tradiciones de la sociedad en la que van a estar inmersos. No respetar ni asumir las costumbres de la población, ${ }^{1}$ especialmente indígena, sin una previa y decidida formación que ponga de manifiesto las ventajas de un nuevo modelo, supondrá el enfrentamiento directo a una trayectoria histórica que debe merecer todo el respeto de quién, en ese momento, puede tomar decisiones. Hay que intentar asumir e integrar los marcos agrícolas, urbanos, legislativos, históricos, religiosos, etc. y sólo una vez plenamente justificadas las decisiones implantarlas de manera no traumática. No es correcto, ni útil a largo plazo, intentar identificar un único propietario cuando la comunidad considera que los bienes son del conjunto de pobladores; de uno sólo que les permite al resto aprovecharlos; o de nadie, pues el "Amo" es un ser superior anterior a ellos mismos. La legislación es flexible, cuando los gobernantes lo son, para diseñar modelos específicos capaces de asumir las situaciones existentes; y sólo es cuestión de tiempo, esfuerzos y buena voluntad (a veces incluso es más económico) buscar alternativas viables a realidades concretas.

Dentro de un marco específico propio es conveniente identificar y distinguir algunos de los contenidos que deben incluirse en un proyecto catastral unificado multipropósito genérico. La siguiente relación debe entenderse como una secuencia de referencia, pudiendo abordarse más de un ítem simultáneamente, dependiendo del modelo de catastro que se desee implantar o renovar, en una primera fase o en

1 Complementariamente estos trabajos deberían servir para modernizar la sociedad en algunas líneas específicas: integración de la mujer en el mercado laboral e igualdad en todos los ámbitos. No debe impedirse que pueda figurar como propietaria, pueda vender e hipotecar sus bienes, etc. 
fases posteriores. La redacción de un plan estratégico y los operativos deben consensuarse, incardinarse dentro de un proyecto de gobierno y establecer los mecanismos necesarios para comprobar que se logren las metas previstas:

1. Estudio de la situación actual y justificación de su necesidad:

- Recopilación de toda la información literal y gráfica disponible

- Recopilación de la normativa técnica y legal vigente

- Identificar las diferentes instituciones y/o particulares que tengan competencias en esta materia

- Análisis de los distintos modelos catastrales existentes

- Análisis de los derechos de la propiedad establecidos y formas de defenderlos

- Justificar la necesidad de implantar un nuevo modelo de catastro, revisar el existente o modificar sustancialmente el vigente.

2. Identificar, de manera ambiciosa, los usos y aplicaciones que tendría:

- En una primera fase

- En fases posteriores, ya plenamente implantado y totalmente operativo; sustentado en un proceso de conservación, actualización y coordinación reglado, eficaz y eficiente.

3. Localizar el equipo humano y técnico necesario:

- Identificar los técnicos locales capaces de colaborar

- Seleccionar los técnicos foráneos de acuerdo con un perfil previamente fijado

- Seleccionar los centros universitarios, locales o no, válidos para impartir programas de capacitación, asesoramiento específico y mantenimientos periódicos

- Contactar con empresas reconocidas y solventes capaces de suministrar los equipos técnicos necesarios y el mantenimiento continuado.

4. Diseñar un marco institucional sencillo, preciso y operativo:

- Institución encargada de liderarlo

- Instituciones coordinadas y complementarias

- Instituciones que sean futuros usuarios/clientes, que se convertirán progresivamente en proveedores de información.

5. Redactar un marco legal acorde con las necesidades:

- Definir el carácter universal, limitado, autonómico, municipal, etc.

- Distribución de competencias y responsabilidades

- Fijación principios, unidades catastrales y derechos

- Diseño de procesos que deban estar enmarcados dentro de este ámbito. 
- Régimen de sanciones y penalizaciones por los incumplimientos o ilegalidades que se detecten

- Establecer una metodología sencilla, fiable, transparente, confiable y eficaz para resolver los litigios que se originen

- Establecer con claridad los procesos de gestión catastral, gestión tributaria y gestión recaudatoria; así como las instituciones responsables.

6. Diseño del modelo de valoración a implantar:

- Estudio de los modelos existentes y empleados regularmente

- Diseño y elección de un modelo o modelos: sencillo, ágil, preciso, automatizable, sistemático, universal, fácilmente actualizable, transparente, confiable, comprensible, que cuente con la confianza y respeto del contribuyente.

7. Documentación gráfica a elaborar:

- Recopilación de la documentación gráfica disponible y estudio de su validez

- Selección del soporte gráfico a emplear: cartografía levantada por topografía clásica, restitución, ortofotomapa, imagen satélite, video, etc.

- Elección de las escalas/definición en función del objeto a registrar

- Elección de la información a incluir, en el soporte elegido, imprescindible para cubrir los objetivos previstos en las fases establecidas

- Viabilidad de la gestión automatizada de todo el conjunto

- Análisis del proceso de conservación y actualización que se desarrollará

- Redacción de los pliegos de condiciones técnicas

- Integración de la cartografía en los $\mathrm{WMS}^{2}$

- Establecimiento de un sistema de control de calidad efectivo.

8. Documentación literal a captura:

- Recopilación de la documentación literal disponible y estudio de su validez

- Selección de la información imprescindible para cubrir los objetivos previstos en las fases establecidas

- Titular del-los derecho-s

- Régimen de confidencialidad que debe emplearse

- Viabilidad de la gestión integrada e interrelacionada con las bases de datos gráficas

- Diseño y fomento de los procesos de reutilización de la documentación.

2 WMS:_WebMapService. Es un estándar para publicar cartografía en Internet y las especificaciones están recogidas en OGC (Open Geoespatial Consortium). Es un servicio y no una página web. Se ha de utilizar desde un navegador que admita este servicio. A modo de ejemplo, en la Dirección General del Catastro de España la dirección del servicio es: <http:/ovc.catastro.meh.es/Cartografia/ WMS/ServidorWMS.aspx>. 
- Análisis del proceso de conservación y actualización que se desarrollará

- Redacción de los pliegos de condiciones técnicas

- Establecimiento de un sistema de control de calidad efectivo.

9. Estrategias y calendario:

- Implicación de todos los agentes afectados, en un marco de total consonancia con la sociedad

- Diseñar una estrategia de elaboración e implantación realista, capaz de ser evaluada cuantitativamente.

- Fomento de los procesos de reutilización de la documentación

- Establecer un régimen de responsabilidades

- Elaborar un calendario para diseñar los modelos, implantarlos, estimar su validez, incluir modificaciones y estimar los plazos para aplicarlo de forma universal, dentro de las coordenadas político-administrativas existentes.

10. Financiación:

- Localización de fuentes de financiación interna, externa e, incluso, privada

- Estimación los recursos económicos que podrían obtenerse a través de la puesta en tributación de los inmuebles identificados

- Venta de los productos elaborados.

11. Gestión y conservación:

- Diseño del sistema de conservación de la documentación gráfica y literal elaborada

- Identificación de la información a capturar, en diferentes fases posteriores a la implantación, de forma masiva, automática, económica y fiable, con garantías de permanencia en el tiempo

- Diseño del proceso de gestión coordinada del catastro-registro apoyándose en las instituciones existentes, técnicos especializados y experiencias en otros países

- Diseño de sistemas de difusión y relación con la sociedad

- Búsqueda de alianzas que garanticen el uso y la retroalimentación de la información catastral

- Integración de la sociedad en la búsqueda de una e-administración: hay que hacerla cómplice del proyecto.

Con estos contenidos el catastro se convertirá en la institución de referencia, una infraestructura de información territorial que permitirá el uso del territorio, en su 
concepto más extenso, favoreciendo la toma de decisiones sobre datos objetivos, normalizados y fiables. Con un marcado perfil de e-administración se establece un flujo continuado, seguro y eficaz entre las diferentes partes implicadas, garantizando el acceso a los datos catastrales a todos aquellos que gocen los correspondientes permisos. La disponibilidad de esta información y la accesibilidad a las bases de datos catastrales por los titulares, administraciones y empresas para su empleo en todo tipo de actuaciones no es sólo una finalidad catastral, sino que ésta institución también se beneficia de la misma al fomentar la colaboración de todos los agentes que actúan sobre inmuebles para actualizar su base de datos (Figura 1).

\section{Situación actual y necesidad}

Para conocer la situación actual hay que actuar en varias líneas complementarias que comienzan por la recopilación de la información catastral disponible (gráfica y literal), la investigación de la normativa técnica, los marcos jurídicos establecidos y el escenario administrativo que esté implantado o en fase de desarrollo; aspectos, todos ellos, que se van a analizar a continuación:

\section{Recopilación de información}

Recopilar la información literal y gráfica disponible y, en su caso vigente, no es una de las labores más atractivas; pero es, sin duda alguna, una de las prioridades dado que es imprescindible conocer la situación catastral actual para proceder en consecuencia: "en ocasiones es recomendable dar un paso hacia atrás para tomar fuerzas y poder saltar más lejos". Por recopilar no debe entenderse recoger masiva e inconscientemente los listados, fotografías, planos, planillas, etc., existentes en las diferentes municipalidades, delegaciones de agricultura, hacienda, reforma agraria, notarías, registros y otras instituciones públicas y privadas; se trata de localizar lo que haya, dónde está, cuál es su estado de actualización, que información contienen y para qué se emplea. De esta manera siempre se podrán rescatar aquellos datos que:

- Puedan servir de referencia para solventar posteriores litigios en materia de titularidad y lindes.

- Emplearse en la cumplimentación de la documentación exigible en los nuevos trabajos pues, sin la existencia previa de un comunicado o una reclamación sobre sus contenidos, formalmente estarán en vigor.

- Utilizarse para intentar localizar al titular que figura, o a sus descendientes, con objeto de conocer los posibles derechos que aún mantengan sobre los bienes. 

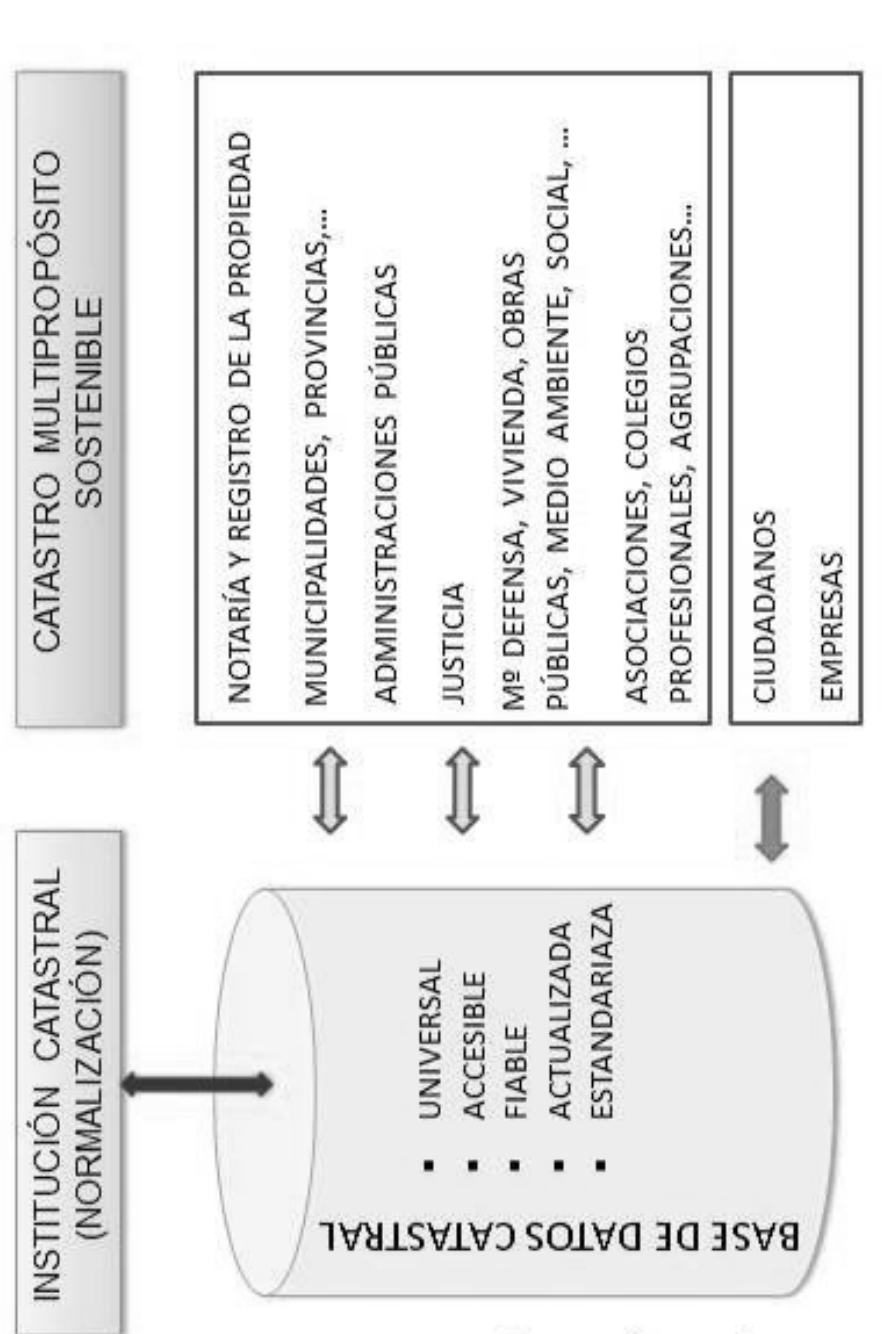

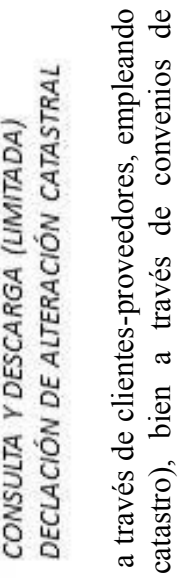

$\geq \quad \frac{0}{0}$

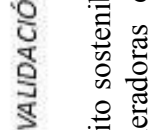

矛

2.

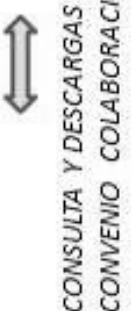

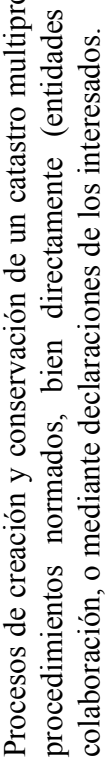

O४ $\perp S \forall \perp \forall O \exists O S \forall Y O O \forall Y \exists N \exists O S \exists N O I O \cap \perp \perp S N I$
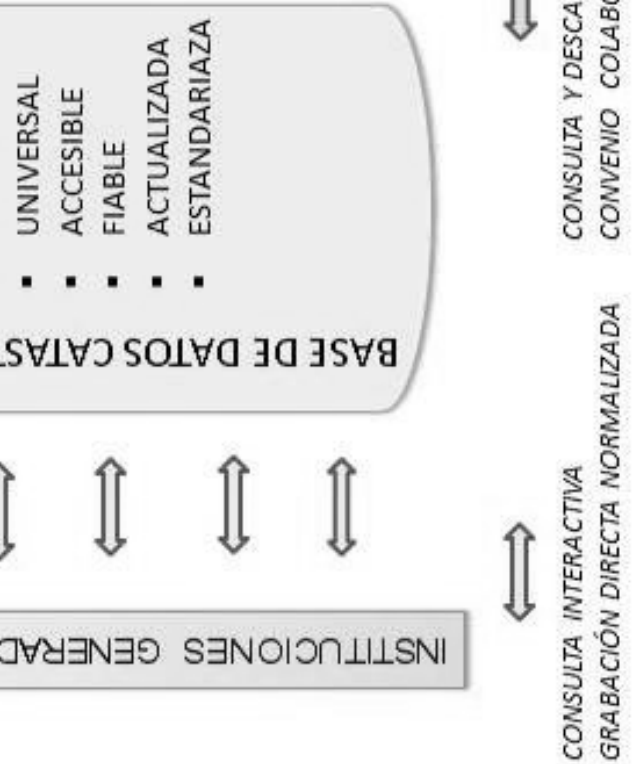

苛 


\section{Normativa técnica}

Para conocer la normativa técnica vigente habrá que recabar información de todos los organismos que tengan competencias en la formación, conservación y gestión en materias relacionadas con el catastro y los bienes inmuebles: institutos geográficos; centros estadísticos; instituciones tributarias; ministerios de agricultura, obras públicas y vivienda; municipalidades; registros públicos de diversa índole, etc.

Durante esta fase no será extraño identificar normativas y pliegos de condiciones obsoletos, faltos de rigurosidad e, incluso, que presenten contradicciones entre las atribuciones y exigencias a cada responsable. Tampoco será extraño detectar rigurosas exigencias en algunos procesos que no encuentran su lógica técnica en una segunda fase de los trabajos: precisiones milimétricas en cartografía 1:5,000, y valoración rústica empleando mapas de usos del suelo a 1:500,000; inclusión como variable explicativa el número de cuartos de baño que tiene una vivienda, y valores de suelo generalizados por manzana, que no tengan en consideración las peculiaridades de fachada, esquineros, irregularidades geométricas, etc.

Toda la información debe localizarse y analizarse, sin pretender anular cualquier actuación o decisión anterior sin un conocimiento previo sobre la cualificación profesional del equipo que lo redactó y el contexto social, económico, político y administrativo en el que se adoptó. En ocasiones habrá sido el conocimiento real de la situación lo que motivó que técnicos cualificados dirigiesen sus actuaciones por determinados senderos, que quizá un "ojo experto" foráneo sólo detecte después de años de trabajo sobre el terreno.

\section{Marco jurídico}

Por su parte, los marcos jurídicos vigentes en materia catastral suelen proceder de situaciones en las que se tomó conciencia de la necesidad de implantar un catastro y se redactaron rigurosas leyes y reglamentos que, en ocasiones, no se llegaron ni a desarrollar formalmente; pues el impulso catastral se abortó antes de poder hacerlo. En cambio, la legislación en materia de derechos de propiedad sí suele ser más precisa y estar plenamente desarrollada y consolidada: clases de derechos, defensa de los mismos, forma de acceso a la propiedad, sistemas de transmisión, hipotecas, etc., dado que la propiedad es la base de todo estado moderno y su defensa uno de los pilares que lo sustenta.

Cierto es que el marco jurídico puede variar de un estado a otro, y que la reglamentación puede haberse desarrollado durante siglos apoyándose en sistemas tradicionales que, en ocasiones, reflejen y respeten costumbres tribales; pero de lo que no hay duda es de que está regulada y que la Administración fomenta y avala su formalización en la medida en que la misma ofrece numerosas ventajas y reduce el número de litigios. 
Hay que resaltar que, aunque todos los implicados son conscientes de esta necesidad, a veces es el propio sistema el que ha convertido la formalización y la defensa de los derechos en un proceso complejo y costoso, del que depende el ejercicio de numerosos juristas y técnicos que sólo buscan favorecer sus intereses personales.

Tan importante como la regulación del proceso técnico es la regulación jurídica de la actividad catastral: contar con una legislación actual, versátil y autónoma que permita ejecutar, gestionar y explotar los catastros. Independientemente de quién tenga las competencias cartográficas, de titularidad, en materia de valoración, o gestione los procesos de coordinación, conservación y actualización; así como la explotación, venta, reutilización o cesión de la información, es imprescindible para tener un catastro universal fiable contar con un marco legal autónomo, en el que queden claramente establecidas las competencias en materia de gestión catastral, tributaria y recaudatoria; fortalezca los procesos de conservación, actualización y coordinación nacionales; tan importantes o más que los de implantación.

\section{Contexto internacional}

\section{Coordinación catastral}

Todo lo anterior debe de enmarcarse dentro de un contexto internacional en el que numerosos países están inmersos: la descentralización administrativa. En Iberoamérica se detectan numerosos procesos de delegación de competencias y responsabilidades desde los órganos de gobierno nacional hacia las provincias, departamentos, municipalidades, etc.; competencias que pueden no llevar asociadas sistemas de financiación que les permitan asumirlas plenamente.

Por este y otros motivos, la gestión tributaria y recaudatoria de la información catastral (que no debe confundirse con la gestión catastral), han sido delegadas y asumidas por las entidades locales. Pero hay que tener presente que son gestiones diferentes, que no tienen por qué coincidir en la misma administración o institución. El ámbito de la gestión tributaria es más amplio, y utiliza la información catastral para sus actividades en materia de impuesto predial, a la que podrán sumarse: impuesto de alcabalas, recuperación de plusvalías, tasas, contribuciones especiales, etc.

Esta clara tendencia encuentra en cada nación su justificación, y cada vez es más sencillo defender la existencia de una institución de ámbito nacional encargada de regular la integración y unificación de los procesos técnicos de las diferentes entidades que han asumido, o podrán asumir la implantación, conservación, coordinación, actualización, gestión y explotación del catastro. De esta forma conviven coordinadas una institución catastral encargada de normar, asesorar y facilitar los procesos de infraestructuras territoriales, con el resto de administraciones, empresas y particulares, que serán los sujetos pasivos del-los impuesto-s, y sus usuarios fina- 
les; a la vez que proveedores de información. Con lo que el sistema que se establece presentará las siguientes características:

- Abierto: permite el intercambio de la información entre quienes la generan y aquellos que la solicitan.

- Desconcentrado: permite el acceso al mismo a través de las distintas entidades públicas del Gobierno Nacional, Gobiernos Regionales y Locales.

- Dinámico: es objeto de actualización permanente por los cambios físicos y legales inherentes al predio.

- Normalizado: permite la uniformidad en los procedimientos de gestión, obtención y tratamiento de la información que genera.

- Estandarizado: contiene estándares técnicos, informáticos, administrativos y legales en los procesos y datos que conforman el Sistema.

- Seguridad: otorga seguridad jurídica a los actos jurídicos referidos a predios y a sus derechos.

Todas estas entidades, públicas o privadas, nacionales o extranjeras, lucrativas o benéficas, deben localizarse e identificarse sus actividades. En ocasiones la creación de una única institución que lidere el catastro, perfectamente coordinada con todas las implicadas, puede ser considerada como un enemigo a los intereses individuales de determinados colectivos; en concreto:

- Algunos abogados que se dediquen a legalizar y titular los derechos sobre los inmuebles. Una institución gubernamental que lo haga de forma rápida, eficaz, segura y gratuita, o con un coste testimonial, puede no ser de su agrado.

- Las entidades financieras podrán ofrecer créditos hipotecarios más económicos cuando el bien inmueble esté identificado e inscrito. En este caso los centros alternativos que ofrecían créditos a más alto interés podrían no ilusionarse con los proyectos catastrales.

- Los custodios de documentación gráfica y literal que, en ocasiones, podrían poner a la venta de forma fraudulenta algunos de estos productos no encontrarán un aliado en una institución que tienda al establecimiento de una relación seria y formal con el ciudadano-cliente a través de la e-administración.

- Los responsables de la estimación de la carga fiscal y de la recaudación, que favoreciesen determinados beneficios fiscales y exenciones en aras de un beneficio propio, encontrarán en las bases de datos automatizadas y confiables una clara oposición a sus intereses.

La relación anterior podría ser una de las más extensas de este texto, pero no es éste su objetivo. Baste decir que la capacidad de invención del ser humano es infini- 
ta, y especialmente productiva en aquellos aspectos que le reporten un beneficio importante y rápido, aún a costa de otros conciudadanos menos agraciados. Por este motivo es imprescindible contar con una administración eficaz y rigurosa que se apoye en datos fiables, procesos objetivos y principios consolidados.

\section{Modelo}

El conocimiento preciso de la situación actual del catastro de un país no se consigue únicamente con un análisis interno. Es necesario contrastarlo con otro más amplio: preciso, profundo, riguroso, sistemático y exhaustivo, de los modelos catastrales vigentes en el mundo y de los sistemas diseñados para defender los derechos sobre los bienes. Lamentablemente no abundan las referencias bibliográficas sobre modelos catastrales, y son pocos los especialistas que puedan ofrecer un asesoramiento de conjunto y contrastado que complemente la visión local con aportaciones que enriquezcan los proyectos dentro del contexto técnico, económico, social, tributario y legal vigente. Aunque recomendable la consulta de pliegos de condiciones técnicas de otros países, la recopilación de información de empresas especializadas en catastro y la ayuda de instituciones encargadas de ofrecer préstamos para la implantación de catastros, hay que ser conscientes de las limitaciones de cada una de ellas:

- Existen pliegos de condiciones sumamente precisos, rigurosos y completos que permitirían implantar un catastro de gran calidad, pero hay que tener presente que las instituciones que los redactaron se encuentran inmersas en sociedades que no tienen los mismos problemas ni son comparables sus necesidades. La formalización de la propiedad no es una inquietud en Francia, en donde la mayor parte de los inmuebles están ya registrados; en cambio, sí es interesante favorecer la defensa de los derechos inscritos y la gestión automatizada de la información catastral para, por ejemplo, acogerse a las ayudas de la Política Agraria Comunitaria vigente en la Unión Europea.

- El acceso a las empresas encargadas de elaborar documentación gráfica o de vender equipos y programas informáticos es interesante, pero deben tenerse en cuenta los objetivos de las mismas, pues han de responder ante sus accionistas. Es recomendable la búsqueda generalizada y tener los conocimientos suficientes en las respectivas materias como para no dejarse llevar por llamativas presentaciones, buenas palabras o favores personales. Al final estos productos se van a convertir en la herramienta base del catastro, y cuanto mejor diseñados y adaptados a las necesidades propias estén, menor número de problemas y mayor número de aplicaciones presentarán en el futuro.

- No es difícil acudir a algunas de las instituciones que tienen competencias en materia de catastro o desarrollan programas divulgativos sobre el mismo; entre ellas puede citarse: Direcciones Generales de Catastro, Grupo de Trabajo de 
Administración del Territorio (WPLA), Banco Interamericano de Desarrollo (BID), Federación Internacional de Geómetras (FIG), etc., pero hay que ser conscientes de que en ninguna de estas se encontrará un modelo catastral trasladable íntegramente; aunque sí información rigurosa y precisa, así como (en ocasiones), experiencias exitosas concretas.

Conocidos los modelos, las ventajas que tienen sobre el propio, las dificultades de implantación y conservación, los litigios que han conllevado, etc., se está en situación de tomar la decisión de diseñar uno nuevo o adecuar el existente a las necesidades actuales y a los requerimientos que se le exigirá en el futuro. En esta fase hay que ser lo suficientemente juicioso, flexible y riguroso para no dejarse influenciar por presiones interesadas y dirigir las actuaciones en la línea de obtener un catastro moderno, fiable, eficaz y simple. Para ello se debe contar con un equipo pluridisciplinar propio, en su caso asesorado por expertos foráneos, que sean capaces de identificar los recursos humanos disponibles para llevar a cabo el proyecto que se va a acometer. No es lógico diseñar un proyecto puntero si no se dispone de técnicos cualificados para elaborar la documentación gráfica, recopilar los datos alfanuméricos, asignar un valor a todos los inmuebles, informatizar los datos e interrelacionarlos, procesarlos y ponerlos en valor, conservarlos, implementar nuevas aplicaciones, etc. Adquirir los equipos físicos y los programas informáticos puede ser un problema económico, de más o menos difícil solución, pero, hasta cierto punto, rápido. En cambio, la formación de un personal cualificado capaz de, no sólo usar aplicaciones, sino de desarrollar los trabajos con conocimientos en materia de Geomática, Valoración, Fiscalidad y Derecho, no es sencillo ni inmediato. Éste es el principal problema (el capital humano) con el que se enfrentará quién decida acometer proyectos de este tipo.

Un problema que, en ocasiones se complica cuando los gestores locales de catastro se ciñen a modelos, también locales. El catastro ha evolucionado enormemente en las últimas décadas, y el padrón de los recibos prediales sigue siendo un objetivo inmediato; pero no es el único producto que puede generar y que pueden demandarle. Los usos y aplicaciones del dato catastral, entendido el catastro como una infraestructura territorial multipropósito, son muy numerosos. Y cada vez son más pues sobre la base de su utilidad se apuntala la concepción, diseño y puesta en ejecución de nuevos servicios.

\section{Usos y aplicaciones}

\section{Dato catastral}

El dato catastral es la piedra angular de esta infraestructura territorial. El dato, normalizado y fiable, que procederá de su captura en campo, de su declaración por los 
titulares, de su inclusión vía convenio, de su consulta a otras administraciones, etc., el que servirá para nutrir, mantener actualizado y útil el catastro multipropósito. Hay que ser conscientes de que una vez finalizada la captura de la información de 50 o 100 millones de unidades inmobiliarias no se pueden volver a visitar para recoger datos relativos a, por ejemplo: estado del acceso, índice de pedregosidad, número de cuartos de baño, cerramientos y carpinterías de las viviendas, etc., para realizar la valoración inmobiliaria. Pero, por otra parte, tampoco hay que ser excesivamente rumboso con los datos a incluir en las fases de campo, pues su captura, procesamiento, comprobación, gestión y conservación cuesta dinero y tiempo; dos aspectos de los que no se suele disponer en abundancia en ningún proyecto. Hay que identificar las demandas de productos y servicios que las administraciones, las empresas y los particulares pueden formular al catastro e intentar, en la medida de lo posible, diseñar un modelo multipropósito que las satisfaga, que vaya creciendo y perfeccionándose a la par que crecen y se perfeccionan las demandas (Figura 2).

Este planteamiento no es filantrópico: tiene una vertiente económica y otra funcional. La primera se sustenta en el hecho de que la información disponible puede ser puesta a la venta y pocas empresas o administraciones elaborarán cartografía o estimarán valores inmobiliarios si ya existe a una escala adecuada a sus necesidades, o se conoce el valor más probable de mercado que alcanzaría el bien si se pusiese en venta. El segundo aspecto es meramente egoísta; el hecho de que existan clientes que soliciten los datos fuerza a la propia administración responsable del catastro a mantenerlo actualizado; pero también son aquellos los que, de manera voluntaria o forzada, suministrará información para realizar una adecuada conservación, convirtiéndose en clientes-proveedores; por ejemplo:

- Las oficinas de notaría necesitan datos sobre el titular catastral de una parcela para formalizar una escritura de compra-venta. Si se les suministran — de forma gratuita o no-, se les exigirá que comunique la alteración al Catastro para que éste actualice su base de datos con la alteración notificada y documentada.

- Los encargados de realizar obras civiles: carreteras, líneas de ferrocarril, embalses, expropiaciones urbanísticas, etc., requieren datos sobre titularidades de fincas, superficies, cultivos, usos y valores para iniciar con las compras de los inmuebles o formalizar los trámites expropiatorios. Se condiciona la venta o cesión de los mismos a cambio de que reflejen las obras nuevas y las mejoras realizadas en la documentación catastral; por ejemplo: regadíos implantados, tramos de carretera ejecutados, terrenos destinados a la construcción de embalses, nuevas calles o polígonos industriales...

- Los padrones de las riquezas rústica y urbana pueden ser utilizados para establecer recargos tributarios sobre: alcantarillado, recogida de residuos sólidos, alumbrado, arreglo de caminos rurales, subvenciones agrícolas, etc. De esta 


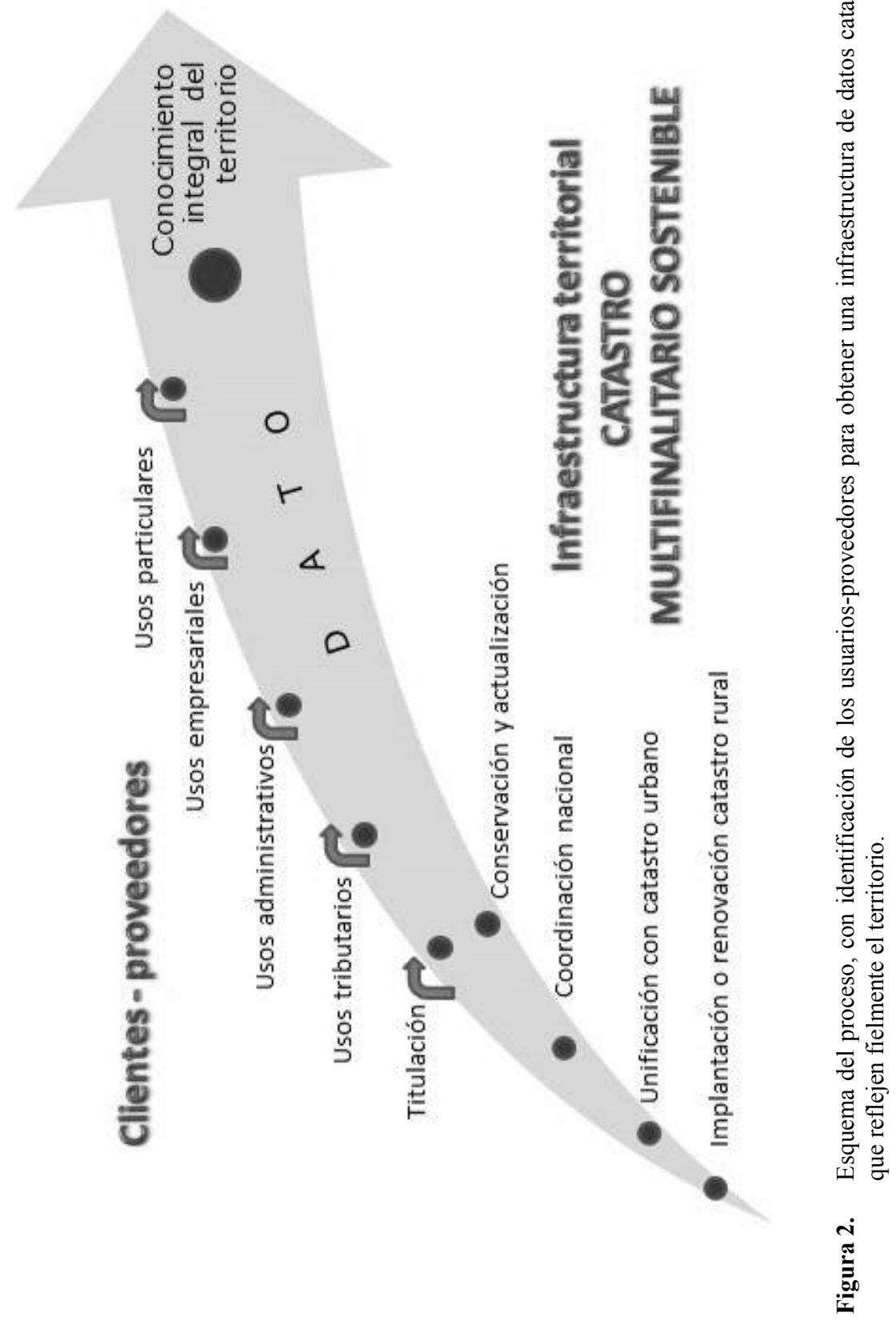

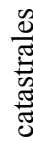


forma la administración o empresa encargada de poner al cobro y recaudar las cantidades fijadas se ocupará y preocupará de que los listados de titulares estén actualizados y de que figuren correctamente las direcciones fiscales.

- Las recalificaciones de suelo para usos urbanos, con las consiguientes plusvalías, se podrán repartir y recuperar para usos sociales de la comunidad, a la vez que se actualiza la información (datos catastral): parcelación, nuevos usos y aprovechamientos, nuevos titulares, nuevos valores, y cuantificación objetiva de la plusvalía generada.

En resumen: la venta o cesión de datos es un acicate para que la propia administración responsable mantenga la base de datos actualizada y fiable; pero a la vez sirve para recaudar fondos e información relativa a las alteraciones que se hayan producido y no declarado.

\section{Utilidades}

El número y la naturaleza de las aplicaciones que puede tener un catastro multipropósito son enormes, tanto durante sus primeras fases de implantación como en otras posteriores, cuando esté plenamente consolidado. Por otra parte, la experiencia ha demostrado que un catastro "nunca muere"; siempre será una fuente de información (con la fiabilidad que corresponda), que permitirá conocer la realidad inmobiliaria, en una disensión temporal amplia, del territorio y de sus pobladores.

La historia ha demostrado que muchos proyectos catastrales, bien diseñados y desarrollados correctamente, han ido agonizando paulatinamente cuando el gobierno que los heredó bien no comprendía su importancia, bien no estaba interesado en su conservación y mejora, o bien no dotaba presupuestariamente esta actividad. El origen de estas situaciones se suele encontrar en el desconocimiento del alcance de esta herramienta para el desarrollo socioeconómico de la población, o en un interés partidista por ocultar la riqueza inmobiliaria; ambos difícilmente justificables en la actualidad. Para evitar estas situaciones hay que incidir en la capacitación a todos los niveles y en la reseña (y explicación) de todas aquellas necesidades que podrá satisfacer un catastro multipropósito. De esta forma los responsables identificarán los usos inmediatos y futuros, el calendario en que se obtendrán estas metas y qué decisiones, herramientas y procesos deben acometerse para lograrlas. Actividades que no pueden entenderse como independientes, fruto de una única institución, pues el catastro no lo es. Deben interpretarse como un proyecto integral, un catastro único, universal, dinámico y sostenible, que agrupe a todos aquellas administraciones que tienen al territorio, en su concepto más amplio, como elemento de referencia.

Son muy numerosos los usos de esta ingente base de datos georreferenciados; tantos que su mención incrementaría desproporcionadamente este documento, por 
lo que es mejor hacer alusión solo a los grandes bloques temáticos en los que se utiliza asiduamente: ${ }^{3}$ finanzas; agricultura y forestal; propiedad, derechos y limitaciones; plusvalía, expropiación, civil, territorio, social, defensa, medio ambiente, protección civil, usos privados, etc.

Aunque de forma somera es oportuno hacer mención a dos de las utilidades inmediatas, no tributarias, que más han ayudado a que diferentes estamentos de la Administración defiendan no solo la confección de un catastro fiable, sino que han presionado para que se mantenga actualizado, participando activamente a través de procesos de coordinación y colaboración. Estas son la ordenación territorial y la formalización de la propiedad inmobiliaria.

Dentro del ámbito de la ordenación del territorio las actuaciones en las que puede ser utilizada la información gráfica y literal de un catastro son inmensas. Hay que entender la ordenación territorial no sólo como una actuación a nivel de los núcleos urbanos consolidados que se encargue de definir las naturalezas de los inmuebles y aquellos usos prioritarios o preferentes en determinadas zonas de la ciudad. La ordenación territorial es la herramienta cardinal para establecer las grandes líneas de los desarrollos futuros; los criterios para regular la evolución de las ciudades y sus entornos; las inversiones en materia de infraestructuras (transporte, agua, energía, telecomunicaciones, etc.) y espacios productivos; la estimación, cuantificación y modelización de desastres naturales (catástrofes); la protección del patrimonio histórico-artístico; atraer y fomentar la inversión productiva; promover el desarrollo turístico, etc. Hay que conseguir consolidar el país como un territorio articulado, integrado y cohesionado en los ámbitos físico, económico y social dentro de su entorno geográfico natural; de tal forma que ello repercuta en un desarrollo social equilibrado que mejore la calidad de vida de sus ciudadanos, estimulado por una mejor y más eficaz gestión de los recursos públicos.

De una manera muy especial hay que resaltar la importancia de un catastro multipropósito en el desarrollo social y económico de un país en su conjunto. La identificación precisa del bien y de su titular beneficia el crédito hipotecario en diferentes vías complementarias:

- Reduce el riesgo para la entidad financiera

- Incorpora miles-millones de nuevos agentes productivos de crédito

- Favorece la disminución de los tipos de interés aplicables

- Incrementa los plazos de reembolso

- Sustituye el crédito personal por el inmobiliario

- Dinamiza la economía.

3 Un desarrollo más detallado de las utilidades de un catastro multipropósito puede localizarse en el texto Catastro, propiedad y prosperidad (2007) o Catastro inmobiliario (2011) de M. Alcázar. 
La entidad financiera brinda, al empresario agrícola que quiere mejorar su explotación o al ciudadano que intenta acceder a una vivienda digna, mediante el sistema crediticio inmobiliario, una alternativa real y asumible; pero aquella no se quiere encontrar con elevados índices de impagados, inmuebles que pasen a su propiedad o interminables procesos de embargo y subasta: su negocio es la gestión de dinero y no la gestión y venta de inmuebles. Las administraciones podrían apoyar, mediante subvenciones, determinados proyectos, perfectamente definidos y con un calendario preciso; pero para que el mercado se dinamice es imprescindible la entrada del sector privado. Y, para ello, deberán cumplirse los compromisos firmados, en principio fiel reflejo de que se están consiguiendo los objetivos previstos por cada una de las partes: el banco sus cuotas periódicas, el ciudadano su vivienda y el agricultor la mejora de su explotación. En consecuencia, no basta sólo con identificar el inmueble y los derechos de un titular sobre el mismo para la entrega de dinero avalado por el bien; es necesario informar, formar y concienciar a los implicados de los riesgos y las responsabilidades que se asumen.

Hay que ser conscientes de que todo lo expuesto no se puede alcanzar en una primera acometida. Son necesarios muchos años en los que se vaya avanzando, recabando información, creando cultura catastral y, especialmente, confianza en el producto. Si ésta se consigue los demás lo demandarán; en caso contrario, cada particular o administración elaborará su cartografía, indagará los usos, estimará los valores, buscará respaldos para la solicitud de créditos, etc. Si se desea tener un estado moderno, integrado en el marco internacional, se necesita un catastro fiable y multipropósito; pues qué menos saber lo que hay, donde está, cuánto vale y de quién es.

\section{Equipo}

El capital humano es, ha sido y, especialmente, será una de las prioridades de cualquier sociedad. Los profesionales no se forman en unos días, ni en unas semanas de cursos intensivos; son meses lo que se tarda en cualificar un especialista capaz de realizar los trabajos, dirigirlos y aportar ideas o sugerencias que sirvan para resolver problemas o desarrollar nuevas aplicaciones. El experto en catastro debe ser, hasta cierto punto, un híbrido de: topógrafo, agrónomo-forestal, arquitecto, jurista, fiscalista, geógrafo, informático y economista; pero todo en su justa medida.

Lamentablemente no suelen existir centros de formación integral en catastro. Lo normal es que en distintos programas reglados de enseñanza universitaria se impartan conocimientos superficiales de algunas de estas materias, y profundos de otras, en la línea del currículo establecido. Obviamente poner en manos de "bien intencionados" técnicos una apuesta de esta índole no es recomendable en ningún sitio; más aún, es francamente desaconsejable en aquellos países en los que los intentos anteriores hayan fracasado con las consiguientes repercusiones en el ministerio de 
finanzas, agricultura, institutos geográficos, etc., y la pérdida de prestigio y credibilidad de la administración responsable. Es conveniente, antes de abordar un proyecto de este tipo, identificar los titulados más acordes con las necesidades, contar con la experiencia de técnicos catastrales locales y otros foráneos y, dentro de un marco universitario reglado, capacitar un equipo en:

- Transmitir los conocimientos adquiridos

- Preparar técnicos de campo y gabinete que desarrollen los trabajos

- Fomentar la iniciativa privada local encargada de abordar los proyectos que se liciten

- Favorecer la contratación de técnicos especializados en catastro en las municipalidades para que gestionen la documentación, informen a los contribuyentes y mantengan actualizada las bases de datos

- Obviamente, convertirlos en responsables administrativos con diverso nivel de decisión.

El programa formativo contemplará una parte general, a la que se añadirá otra local que analizará las problemáticas específicas del sector inmobiliario en el que está inmerso; por ejemplo: Costa, Sierra y Selva. Y no solo para "tramitar" el catastro. Deben estar capacitados e incentivados para añadir, de forma progresiva, automática, económica y fiable, información complementaria que favorezca el crecimiento paulatino de las bases de datos territoriales. Con ello se conseguirán nuevos logros que incrementarán los usos y aplicaciones del catastro, con lo que se demandará y todos estarán interesados en conservarlo actualizado, fiable y riguroso.

Una vez formados los equipos directivos y los de trabajo, los centros de enseñanza podrán seguir colaborando en la línea de desarrollar nuevas aplicaciones, poner en práctica proyectos concretos y puntuales, mantener programas específicos en materia de valoración, geomática, fiscalidad, etc., importando o exportando ideas, proyectos, normativas, pliegos de condiciones, a otras instituciones nacionales o internacionales. Por otra parte, la colaboración de las universidades ${ }^{4}$ aporta un marcado grado de credibilidad en el nivel de los técnicos que van a desarrollar los trabajos catastrales, lo que repercutirá en la confianza hacia el producto elaborado, disminuirá el grado de incertidumbre sobre la información y favorecerá el uso del mismo para el respaldo de compra-venta, la solicitud de hipotecas inmobiliarias, la adquisición de cartografía para proyectos específicos, y la entrada de dinero extranjero que tendrá confianza en que lo que compra: "está allí, es de esa forma, tiene esta superficie, era de D. Fulano y vale tanto". 
Por último, y abundando en lo desarrollado anteriormente, es interesante resaltar dos aspectos:

- Hay que fomentar la permeabilidad de conocimientos, experiencias y metodologías entre los juristas, los técnicos y los informáticos. Están obligados a entenderse y a coordinarse en aras de obtener un producto útil para la sociedad.

- La Informática y la Geomática son herramientas, y son ellas las que deben adaptarse a las necesidades del catastro; no al contrario.

\section{Marco institucional}

La Administración y sus trabajadores tienen que estar al servicio de los ciudadanos, en este caso también contribuyentes: no se crea un organismo y se le asignan competencias; es la demanda de la sociedad o la justificación de una clara necesidad de información, documentación o servicios lo que debe motivar la existencia de una determinada dirección general, secretaría, consejería, ministerio, instituto, etc. Una vez hecha esta reflexión la institución que se cree para realizar un determinado trabajo debe ser: fuerte, eficaz, eficiente, moderna, sencilla, accesible y ambiciosa, situación que se alcanza cuando:

- Existe un apoyo claro y preciso desde las instancias más elevadas del gobierno

- Quedan claramente definidas las competencias y el ámbito territorial de actuación

- Cuenta con un equipo nacional plenamente cualificado, responsable y motivado

- Se plantea metas alcanzables articuladas en programas que puedan evaluarse periódicamente.

Teniendo en consideración estas premisas hay garantías para que el catastro se "construya" y se convierta en una herramienta multifinalitaria dinámica, útil para la administración, las empresas y los particulares, estimulando la recuperación y el desarrollo económico perseguido.

Para lograr estos objetivos hay que disponer de un escenario adecuado; contexto que no siempre es posible de lograr. Varios son los aspectos a tener en cuenta en gran parte de los países que incluyen entre sus metas inmediatas la implantación de un catastro:

1. Algunos se encuentran inmersos en complicados procesos de descentralización administrativa, que bien diseñados y puestos en la práctica suelen aportar un importante valor añadido al conjunto. En cambio, si han sido impuestos por presiones políticas; se han abordado sin una reflexión y un programa consensuado; se les ha transferido competencias a las administraciones provinciales, departa- 
mentales, autonómicas o municipalidades, pero no se las ha dotado de recursos económicos para que las puedan abordar; no se ha definido un nítido marco de atribuciones para que no se dupliquen o tripliquen las mismas sin que se difuminen las responsabilidades; o, simplemente, no se debe este movimiento descentralizador a que: "son pocos los puestos políticos-administrativos de relevancia y demasiados los candidatos", el proyecto es coherente dentro de una línea de aproximación al ciudadano. Más administraciones y empleados deben servir para reducir los trámites y facilitar las gestiones; no para complicar aún más cualquier iniciativa: la entidad administrativa debe nacer para cubrir una necesidad; no hay que crear una necesidad para justificar la institución.

2. De forma general hay que hacer mención a un hecho de todos conocido, y estudiado por la organización Transparency International, ${ }^{5}$ como es la corrupción. En un último documento, elaborado y publicado se analiza la situación asignándole a cada país un índice que puntúa la corrupción estimada entre un valor de diez, cuando es mínima, y cero, en el caso de que sea máxima. El resultado es francamente desalentador para los países en vías de desarrollo pues cinco de cada diez de éstos no alcanzan un 3 sobre 10; académicamente hablando: "muy deficientes". Obviamente esta situación complica desmesuradamente cualquier iniciativa a tomar, repercute en su prestigio y en el nivel de credibilidad y crédito que goce en el extranjero - lugar a donde debe recurrir para conseguir financiación externa-. Admitiendo que la corrupción puede estar presente en casi todos los niveles, la existencia de un catastro fiable favorecerá la transparencia en la medida en que no será posible defraudar en el impuesto territorial que se establezca; se reducirán los trámites y los costes en los procesos de formalización y transferencia de la propiedad; se garantizará la misma sobre documentos fiables; se podrán gestionar programas sociales con mayores garantías; se recuperaran las plusvalías que se generen a los actos administrativos; y se dispondrá de una base de datos única, universal y verídica con la que contrastar cualquier actuación de los ciudadanos y de la administraciones.

3. El catastro no es algo nuevo en prácticamente ningún lugar $\mathrm{y}$, aunque deficiente e incompleta, existirá documentación antigua elaborada por alguna-s instituciónes nacional o municipal-es. Quien custodia la información puede aprovecharse de la misma y justificar parte de su existencia y del personal adscrito sobre la base de su elaboración, gestión y conservación. La problemática se acrecienta cuando no es un único organismo el que realiza estas actividades, sino que son varios y es necesaria una correcta coordinación; coordinación que la realidad se encarga de poner de manifiesto sus dificultades, aunque esté perfectamente regulada, cada institución tiene sus objetivos, sus prioridades y sus intereses. Por 
lo tanto, la institución catastral ha de tener un papel de coordinación y estandarización de los procesos, que cada institución generadora de catastro desarrolle su actividad conforme a sus criterios y planes, pero que el producto generado, el dato, sea fiable, accesible y estandarizado para ir construyendo, poco a poco, la realidad territorial nacional, tal y como si fuese un puzle, en el que cada pieza sea un predio que conforma un catastro único, pues el territorio lo es.

4. Ante la sensación de desamparo que puede ofrecer la administración responsable, y la imperiosa necesidad de recaudación en muchas entidades locales, no es extraño que las municipalidades (o incluso distritos dentro de una ciudad), aborden la confección de un catastro urbano incentivado por "expertos locales" que aportan ideas - más o menos contrastadas-, pero que en la práctica suelen tener buenas intenciones pero escasa experiencia. El resultado, aunque supuestamente válido momentáneamente, no cumple los niveles de universalidad ni integración que deben perseguirse en cualquier iniciativa de este tipo, y los costes suelen incrementarse desproporcionadamente a medida que se desarrollan los trabajos, con la creciente posibilidad de suspenderlos en el momento en que se acaben los recursos económicos destinados a ese fin, cambien el signo político la municipalidad o se compruebe que los resultados no son tan espectaculares como se preveían. Esta reflexión no debe entenderse como una oposición a la iniciativa privada ni al trabajo empresarial, muy al contrario, hay que incentivarla y apoyarla en todos los foros; debe entenderse como una crítica a modelos catastrales "personales" desarrollados de acuerdo con los criterios, intereses o capacidades técnicas y humanas de quien los propone. Los catastros elaborados no podrán ser integrados en un nivel de información superior, y la modernización de los mismos no es una mera informatización de los datos; es algo más: un proceso enfocado al uso pluridisciplinar para alcanzar los objetivos propuestos de forma efectiva y eficiente.

\section{Conclusiones}

La existencia de instituciones relacionadas con la agricultura, la propiedad, el urbanismo, la tributación inmobiliaria y la gestión del territorio, etc., en ocasiones plenamente consolidadas y operativas, no debe desaprovecharse. Lo recomendable es establecer o fortalecer la interconexión, apoyada en una estrategia efectiva, entre todas ellas y una única institución catastral que las coordine (no que las absorba o suplante), a la que se pueda exigir responsabilidades sobre la base de procedimientos reglados.

El catastro de hoy día ha de ser percibido como una "infraestructura de información territorial". De la misma manera que las infraestructuras clásicas - carreteras, ferrocarriles, redes eléctricas, etc.- resultan básicas para la comunicación y el desarrollo de las actividades humanas, es imprescindible que las sociedades moder- 
nas desarrollen sistemas de información territorial sobre tecnologías informáticas y telemáticas, comunicados entre sí, que permitan, gracias al conocimiento del territorio, la adopción de decisiones, contribuyendo de manera eficaz al desarrollo de la actividad humana, la economía y la protección del medio ambiente.

La institución catastral debe integrarse, ser el catalizador de modernización de la administración tributaria, geomática y jurídica para el uso múltiple de la información por las diferentes administraciones, particulares y empresas. Pero esta modernización implica un cambio que, conforme se ha indicado, exige un apoyo gubernamental decidido, una línea de actuación definida, un equipo pluridisciplinar cualificado y unos plazos de investigación, desarrollo y generalización perfectamente establecidos. Cierto es que casi cualquier iniciativa que se adopte con este planteamiento tendrá éxito pero, en este caso, es especialmente necesario tener presente las consideraciones expuestas pues se tardarán muchos años en elaborar los documentos gráficos y literales necesarios; requerirá cuantiosos recursos económicos a lo largo de varios ejercicios presupuestarios; habrá que vencer numerosas reticencias de aquellos que se han instalado en una situación cómoda que les permite enriquecerse con los trámites administrativos para la legalización de la propiedad, gestión de impuestos, etc.; superar las reticencias de instituciones que pueden considerar mermadas sus atribuciones en materia de cartografía, titularidad pública, y formar un equipo humano capaz de abordar los trabajos. Sin duda alguna estos esfuerzos se verán recompensados con una documentación que la sociedad pueda aprovechar si ella misma colabora en su conservación y actualización. Simultáneamente, no debe olvidarse el aspecto fiscal del catastro, causa de muchas iniciativas abortadas, y por eso es imprescindible fijar un equilibrio entre los deseos — generalizados - de obtener una máxima recaudación a través de una fuerte carga impositiva sobre el inmueble, y la obligación de favorecer la transparencia y la veracidad de los datos que se registren en una primera instancia, y los que se aporten en un proceso de conservación ulterior. Hay que intentar no obcecarse en la captación de recursos procedentes de la tributación inmobiliaria directa, y liberar la imaginación hacia la identificación de productos y servicios útiles para la sociedad que puedan comercializarse; independientemente del enorme valor añadido que aporta conocer el territorio para tomar decisiones objetivas pudiendo, en muchas ocasiones, calibrar los efectos antes de ejecutarlas. Sin duda alguna la puesta en marcha de un catastro multipropósito sostenible es una de las mejores decisiones que puede adoptar un responsable político.

Se ha dejado para concluir este documento la exposición que realizó don Zenón de Somodevilla, Marqués de la Ensenada (promotor del conocido como "Catastro de Ensenada") al Rey, en 1743: "He dejado para lo último lo que en mi sentir debe ser primero que todo, y es catastrar las Castillas... /... La empresa del Catastro ni es breve ni es fácil, pero no es imposible ni costosa para los pueblos...". 


\section{Bibliografía}

Alcazar, M. (2007). Catastro, propiedad y prosperidad, Ed. Universidad de Jaén, España.

Alcazar, M. (2011). Catastro inmobiliario. Editorial Caja Rural, Jaén, España.

Alcazar, M. (2012). Manual de valoración inmobiliaria. Ed. Delta Publicaciones. Madrid, España.

De Soto, H. (2001). El misterio del capital, Ed. Península, Barcelona, España.

Dirección General del Catastro de España. Revista Catastro. Madrid, España, $<$ http://www.catastro.meh.es/esp/publicaciones.asp $>$.

Ponencias del "Master en Catastro, Urbanismo y Valoraciones" y del "Master Internacional en Catastro Multipropósito y Avalúos", 2014, Universidad de Jaén, España, <www.mastercv.org $>$. 